\title{
Separation Anxiety Disorder
}

National Cancer Institute

\section{Source}

National Cancer Institute. Separation Anxiety Disorder. NCI Thesaurus. Code C35014.

An anxiety disorder characterized by recurrent excessive distress due to fear of separation from the home or from major attachment figures; the distress is developmentally inappropriate and causes impairment in social, academic, or other areas of functioning. 